This item was submitted to Loughborough's Research Repository by the author.

Items in Figshare are protected by copyright, with all rights reserved, unless otherwise indicated.

\title{
Reduction of impacts of oil and gas operations through intelligent maintenance solution
}

PLEASE CITE THE PUBLISHED VERSION

https://doi.org/10.1145/3233740.3233747

PUBLISHER

(c) Association for Computing Machinery (ACM)

VERSION

AM (Accepted Manuscript)

LICENCE

CC BY-NC-ND 4.0

REPOSITORY RECORD

Eyoh, Jeremiah, and Roy S. Kalawsky. 2019. "Reduction of Impacts of Oil and Gas Operations Through Intelligent Maintenance Solution”. figshare. https://hdl.handle.net/2134/33916. 


\section{Reduction of Impacts of Oil and Gas Operations through Intelligent Maintenance Solution}

\author{
Jeremiah Eyoh \\ Electrical, Electronics and Systems Engineering \\ AVRRC Research Group \\ Loughborough University, Loughborough, UK \\ +441509635674 \\ j.e.eyoh@lboro.ac.uk
}

\author{
Roy S. Kalawsky \\ Electrical, Electronics and Systems Engineering \\ AVRRC Research Group \\ Loughborough University, Loughborough, UK \\ +441509635678 \\ r.s.kalawsky@lboro.ac.uk
}

\begin{abstract}
Impacts of oil and gas production operations are always very obvious when there is imbalanced operation, uncontrolled stoppage or catastrophic failure of the system during normal operations. These impacts may range from high flaring and venting of associated petroleum gas, oil release or spillage, equipment damage, fire outbreak to even fatality. Possible causes of imbalanced operations or system failure are categorised into process upset, system degradation, ineffective operation and maintenance procedures and human errors. Effective maintenance strategy integrates major components of the system; people (human factors), operation and maintenance procedures (process) and production plant (technology) to develop an intelligent maintenance solution that is capable of monitoring and detecting fault in the system at incipient stage before operational integrity is compromised. This paper deploys data-based analytics technique to develop condition-based predictive maintenance system to monitor, predict and classify performance of gas processing system. Exhaust gas temperature (EGT) of Gas Turbine Engine (GTE) is one of the operating and control parameters associated with efficiency of the GTE operation. The EGT is measured using several thermocouples, temperature sensors spaced equidistant around the circumference of the exhaust duct of the GTE. Neural network technique of multisensory data fusion is integrated with intelligent maintenance system to monitor performance of GTE, detect fault and classify performance of GTE to optimal, average and abnormal performance.
\end{abstract}

\section{Keywords}

Exhaust gas temperature, gas flaring, Gas turbine engine, incipient fault, intelligent maintenance, multi-class classification, neural network, oil and gas, reliability, thermocouple sensors.

\section{INTRODUCTION}

Oil and gas release, gas flaring and venting have been observed and accepted as inexorable parts of the processes in all phases of oil and gas production operations; drilling, producing, refining, NGL/LNG extraction and petrochemical products processing. The flared and vented gas, known as associated petroleum gas (APG), which is entrained in crude oil and is released when oil is brought out and processed, has lots of economic values [1].

Oil and Gas production and Processing Plants or systems are close, complex and hierarchically organised systems, bound to decay from stable state (order) to chaotic state, tending to maximum entropy, having stiff operating parameters, resistant to stresses within narrow boundaries and are susceptible to small, unpredicted perturbations [2]. This system's degradation affects systems' performance, reliability and availability, leading to low productivity due to inconsistent operations. It also has serious impact on the volume of APG flared or vented which in turn leads to environmental degradation. Ineffective maintenance techniques grossly compromise reliability and availability of the production system, which ultimately makes it difficult to optimise asset utilisation in the production facility [3]. According to [4], 'Flaring and venting of associated petroleum gas occurs as a safety measure to safely dispose of gas during emergencies or during the breakdown of machineries",

Maintenance and reliability challenges of oil and gas processing systems seem to negate the envisaged benefits of deployed advanced, innovative technologies and processes, due to inability of the extant maintenance practices to proffer optimal solutions to the problems during operational phase of the systems' life cycle [5].

Condition-based maintenance models have been developed and used in many industrial systems to elucidate maintenance and reliability challenges. Artificial Neural network (ANN) technique of multisensory data fusion is integrated with intelligent maintenance system to monitor performance of GTE, detect fault and classify performance of GTE to optimal, average and abnormal performance.

\subsection{Impacts of Reliability and Maintenance Problems in Oil and Gas Systems}

In Nigeria, industrial systems maintenance has been a destructive and chronic menace that has plagued oil and gas industries and even the economy of the country at large. The maintenance and reliability challenges are owed to ineffective maintenance techniques that are being practiced in the sector. These practices are very expensive, wasteful and in most cases introduce faults to the systems in the course of maintenance exercise due to human factors.

\subsection{0-Day Performance Monitoring of one of the Gas Plants in Nigeria}

The NGL extraction/processing plants are set up to gather and process APG from several oil production facilities. One of such plants was designed to process maximum of $650 \mathrm{mscf}$ (million standard cubic feet) of gas per day and produce $25000-30000$ barrels of NGL per day. The system consists of ten gas turbine driven compressors of which nine were functional during the period of reliability assessment of the plant. Within this period, a total of thirty six unplanned shutdowns were recorded. A greater percentage of these unplanned stoppages was as a result of gas turbine failure due to defective or degraded components. In this system, a progressive decrease in speed of the gas turbine is an indication of present of slow developing fault in the system. It is partly an upshot of gradual decrease in exhaust gas temperature (EGT) of the GTE. 


\section{Approaches to APG Flaring/Venting Reduction/Elimination}

APG gathering for NGL/LNG extraction has really reduced the volume of flared and vented gas, due to deployment of the advanced processing systems, other best practices and procedures. In line with these breakthroughs in the industries, gas flaring and venting could be seen as inevitably breaking of boundary between oil and gas processing system and the ecosystem or physical environment in a "controlled" manner when the safety of the operations are threatened due to unnecessary upset; or uncontrolled manner when there is a catastrophic failure of the processing system due to component degradation or human factor.

\subsection{Boundary design of oil/gas production system for Fail-Safe Operations}

Understanding the basic operations of oil and gas production systems helps in appreciating the complexity of the system; from exploration, development, production and processing, storage and transportation and marketing. Oil and gas production system comprises people, plant (structural, architectural, control system, safety system), Process (oil/gas, operating procedures, standards and regulatory requirements), environment (local and global communities/ecosystems), and government policies and license requirements. Generally, the assessment of economic viability and technical feasibility to safely extract hydrocarbons is complex including numerous impacting variables that play in stochastically [6].

Hazard of operations, dynamics of the processes and stiffness of operating boundaries make the system dangerous when there is an interaction outside of the designed boundaries of the system, that is, uncontrolled breaking of operating boundaries or designed containment. Effective and optimal control of the system involve monitoring the internal dynamics of the system through its critical parameters or variables (temperature, pressure, liquid levels, flow, vibration, speed, etc.) using sensors and regulating the behaviours or forcing the system's operations to remain within the defined boundaries using actuators or final control elements. Though these systems are always closed and highly pressurised, one of the critical considerations during design phase is 'Fail-Safe Operations. The fail-safe operations ensure the safety of the system, personnel and environment should there be any process upset, component or system failure or any unbalanced operations. Hence, fail-safe operation ensures that operational boundaries are broken safely in a controlled manner whenever there is a system failure.

Typically, gas processing include transporting gas from one vessel to another under pressure in pipelines, by increasing the pressure using compressors; heating and cooling for NGL/LNG extraction, storage and transportation. The success of these operations is achieved if the associated risks are properly managed, reliability of the system sustained and human factors effectively analysed and integrated into the design, operations and maintenance of the system. In view of these, gas processing systems are designed such that whenever safety of the system is compromised, the operating boundaries are safely broken in a controlled manner to avoid catastrophic situation. Boundaries in this context are different valves and actuators that allow, prevent, relieve and regulate gas process variables, when there is need, upset or failure. Theses valves are shutdown valves (SDV), blowdown valves (BDV), pressure safety valves (PSV) and pressure relief valves (PRV). Control valves regulate the internal dynamics of the system, by forcing process variables to remain with designed operating envelops. The diagram below in figure 1 show simplified schematic and architecture of oil and gas system respectively, indicating some boundary valves.

System failure and ineffective operational procedures have been highlighted as the primary causes of continued venting and flaring in oil and gas industries [7],[8]. According to Allen [9], previous works done in this area of research indicate that both equipment and operational procedures play key roles in sustaining the current volume of APG flared/vented globally.

\section{Reduction/Eradication of Gas Flaring Condition-Based Predictive Maintenance}

Intelligent maintenance and reliability approach to reduction of impacts of oil and gas operations aim at optimisation of operations and maintenance (O\&M) phase of oil and gas system life cycle using advanced engineering tools and methodologies. This is achieved by integrating major components of oil and gas production system; people (human factors), operation and maintenance procedures (process) and oil and gas production plant (technology) to develop intelligent maintenance solution that is capable of monitoring and detecting fault in the system at incipient stage before operational integrity is compromised. Modelling O\&M phase of system lifecycle from the perspective of a managed system makes it easier to utilise certain approaches such as system dynamics, agent-based simulation modelling and model-based systems engineering techniques to proffer optimal solution to engineering systems maintenance challenges. From the control system perspective, gas processing system can be analysed, monitored and its operation optimised using sensors information.

\subsection{Gas Turbine Engine Performance monitoring}

GTEs find their applications both in industrial and aerospace communities. Industrial applications of GTE include driving of high capacity rotary or centrifugal compressors in oil and gas processing plants, generation of electricity while aerospace applications include commercial and military aircrafts. In oil and gas industries, the rotary compressors driven by GTE are used in various applications such as compression of APG for exportation through pipeline, storage, gas injection for reserviour maintenance, gas lifting to enhance oil recovery from reserviour and for NGL and LNG extraction processes. The power, performance and efficiency of GTE characteristic are the upshots of complex interactions of different subcomponents of gas turbine subsystem and the combustion subsystem [10], [11], [12].

Performance monitoring of GTE considers several pertinent parameters which include ambient temperature, relative humidity, suction pressure, mass flow of fuel gas, quality of fuel gas, quality of inlet air to gas generator, compressor discharge pressure (CDP) of the turbine, firing temperature of the gas turbine, speed of shaft which determines the power output of the GTE [13].

This paper focuses on analysis of exhaust gas temperature data from the GTE system using multisensory data fusion to detect performance degradation at the incipient stage so that planned system stoppage could be scheduled to avoid unbalanced operations which may lead to unnecessary plant shutdown.

\subsection{Intelligent Maintenance and Reliability Sustainment}

Intelligent maintenance systems utilise plant engineering informatics to monitor the health condition of the system, diagnose the failing components or system and predict the remaining useful life of the system using failure trajectories of the 
system. The implementation of these systems requires a combination of human factors, maintenance procedure/process and plant (plant information) in a creative manner. The proposed intelligent maintenance model incorporate key factors of integrated system development life cycle (SDLC) into maintenance reliability improvement procedure during operations and maintenance phase of the system life cycle as indicated in Figure 5.

\subsection{Condition-based Predictive Maintenance: An Intelligent Maintenance Solution}

Condition-based predictive maintenance (CBPM) approach is an intelligent maintenance (IM) philosophy that monitors the production system's conditions and performances using sensor signals, detect fault at the incipient stage, estimate and predict the future state of the system. In addition to deployment of advanced engineering tools and techniques to modelling and development of intelligent maintenance solution, it also advocates incorporation of the maintenance system in the product life cycle. Thus CBPM is a holistic approach to enterprise asset lifecycle optimisation and management.

\subsection{Related Works on Intelligent Maintenance System}

A review of past research works on intelligent maintenance system shows that it has been on since year 1998 and in progress with various names such as intelligent maintenance system [14], intelligent prognostic system [15], e-maintenance [16], condition monitoring system [17], condition-based maintenance, predictive maintenance system [18]. These maintenance systems are mostly developed for specific assignments; they are not scalable, portable or applicable to other systems [15]. For instance, commendable successes have been recorded in intelligent maintenance system for commercial and military aircrafts, marine vessels and industrial machinery health condition monitoring and prognostics using advanced engineering principles such as multi-sensor data fusion (MSDF) technology [14], [16], [18]. Bayesian techniques have been used to develop diagnostic model for fault detection and condition based maintenance of offshore wind components [19]. In [20] Bayesian updating method was adopted to monitor degradation of bearings conditions in order to detect incipient fault and predict residual life of the bearing. Bayesian probabilistic model and naïve Bayes classifier have been implemented by [21], [22] for bearing condition monitoring and fault detection. Cascade correlation neural network classifier was found effective for vehicles door system degradation and failure detection [23].

\section{Multisensory Data Fusion for Intelligent Maintenance system}

Applications of multisensory data fusion (MSDF) technology span a wide range; from robotics, automated manufacturing, remote sensing and condition-based maintenance of industrial systems to military applications such as battlefield surveillance, tactical situation assessment and threat assessment. For a drivetrain and high capacity industrial gas compressor applications, for example, sensor data can be obtained from accelerometers, temperature sensors, pressure sensors, flow sensors, and vibration sensors. An online condition-monitoring system combines these observations in order to identify signs of failure, such as abnormal gear wear, shaft misalignment, bearing failure and low performance of the system. The use of such condition-based monitoring is expected to reduce maintenance costs, reduce operational risk and improve safety, improve productivity and reliability [17]. MSDF techniques can be categorised into probabilistic and statistical methods, Least-square and mean square methods and heuristic Methods. The heuristic methods include artificial neural network (ANN), fuzzy logic and approximate reasoning. In this paper, ANN technique of MSDF for GTE system performance classification is presented.

\subsection{Basic Estimation Fusion Process}

Consider a system with $n$ number of sensors, at the sensor node, the following parameters are specified: $\mathbf{Z}_{\mathbf{i}}$ is the observations with, $\mathbf{R}_{\mathbf{i}}$ the covariance matrix of the associated noises

$\boldsymbol{x}$ is the variable to be estimated, and

$\hat{x}$ is the local estimate of $x$, with its covariance matrix $\mathbf{P}_{\mathbf{i}}=\operatorname{cov}(\hat{x})$

Thus the estimation error $\tilde{x}=\hat{x}-\boldsymbol{x}$

For unified fusion model:

$\mathbf{z}_{\mathbf{i}}=\mathbf{h}_{\mathbf{i}} \mathbf{x}+\mathbf{n}_{\mathbf{i}}$

Where: $\mathbf{z}_{\mathbf{i}}$ is the measurement of the $\mathrm{i}^{\text {th }}$ sensor and $\mathbf{\eta}_{\mathbf{i}}$ is the measurement noise

A local estimate is considered as an observation of the estimate and is given by:

$\tilde{x}=\boldsymbol{x}+(\hat{x}-\boldsymbol{x})$

If the new observation $\hat{x}$ is actually the estimate of $\mathrm{x}$, the standard distributed fusion model is given as:

$\tilde{x}=x+(-x)$

Artificial neural network technique of multisensory data fusion for estimation, prediction and classification is very effective due to its supervised learning capability, its strengths and efficiencies include [24], [25], [26];

- Computation on each node of ANN is done concurrently independent of each other.

- ANNs gather knowledge through inspection of the training dataset, makes intelligent predictions on the data and based on this acquired knowledge is able to produce desirable output on new dataset (test dataset).

- With its adaptive capability, they can adjust their weights matrix to efficiently achieve a given task. ANN system adapts by iteratively adjusting the weights in order to improve subsequent results.

- ANN systems are universally considered as approximators with appreciable accuracy.

- ANN systems are non-linear models capable of modelling any complex non-linear relationships.

- ANN models are robust to noise, resilient and fault tolerant

A comprehensive review of neural network classification applications can be found in [27].

\subsection{GTE performance classification for incipient fault detection}

The presence of multiple faults in a system with many interacting variables such as GTE system can make fault identification very complex, especially at the incipient stage of a slow developing or evolving fault. The introduction of ANN that mimics the ability of a biological neuron in the human brains to learn and adapt the changing environment provides an intelligent solution, especially when there is no availability of exact physic-based mathematical 
models of the GTE system [28],[29]. Several methods have been used over the years to solve classification problems; these include statistical classification techniques, Bayesian classification approaches [21], [22], linear classifiers, nearest neighbourhood classifier, support vector machine and neural network based classification techniques.

Classification in machine learning is the problem of identifying similar attributes among many entities in a given set of data and categorising them into classes [30]. Classification process is viewed as a supervised learning with a training set of properly identified observation

Neural network classification techniques include linear perceptron classifier, radial basic network classifier, recurrent network classifier, cascade correlation neural network classifier [23], feedforward neural network classifier and learning vector quantisation network structure [31]. MLP FFNN Classification of GTE System EGT

The ANN adopted in this study is a multi-input-multi-output (MIMO) system developed to monitor and classify GTE system performance in oil and gas processing plant.

In Feed forward MLP neural network classifier, the input vector is fed into the input layer of the network, each input unit $\mathrm{j}$, produces output $V_{j}$, which is equal to the input value $I_{j}$. The output $V_{j}$ is then fed forward to the hidden layer through weighted connections where activation functions determine the final output of the network through output layer. One of the popular activation functions for back propagation network is sigmoidal function $S_{c}$ : $\mathrm{R} \rightarrow(0,1)$ defined by:

$\mathrm{S}_{\mathrm{c}}(\mathrm{x})=\frac{1}{1+e^{-c x}}$

The constant $c$ can be selected arbitrarily and its reciprocal $1 / c$ is called temperature parameter in stochastic ANNs. The value of $c$ affects the shape of the sigmoid function. That is, as $c \rightarrow \infty$, the sigmoid converges to a step function at the origin. For simplicity sake, $c$ is usually set at unity (1).

Let $\mathrm{X}=\left(\mathrm{x}_{1}, \mathrm{x}_{2}, \ldots, \mathrm{x}_{\mathrm{i}}\right)$, be a set of normalised input vector in $\mathrm{n}$ dimensional space which are to be classified into $\mathrm{k}$ different classes, for multi-class classification problem, $\mathrm{k} \geq 3$. The output vector $X$ in $n$-dimensional input space and a unit $j$ in hidden or output layer, the net input $\mathrm{I}_{\mathrm{j}}$ to unit $\mathrm{j}$ is given by:

$\mathrm{I}_{\mathrm{j}}=\mathrm{b}_{\mathrm{j}}+\sum_{i=1}^{n} W_{i j} V_{i}$

Where $W_{i j}$ is the connection weight from the unit $i$ in the previous layer to unit $j$ in the next layer

$\mathrm{V}_{\mathrm{i}}$ is the output of unit $\mathrm{i}$ from the previous layer

$b_{j}$ is the bias of the unit.

With the net input $I_{j}$ to unit $j$, using sigmoidal function, the output $\mathrm{V}_{\mathrm{i}}$ is given by:

$\mathrm{V}_{\mathrm{i}}=\frac{1}{1+e^{-I_{j}}}$

The parameters of neural network are estimated by minimising the error, that is, the difference between the actual output $A_{j}$ and the predicted output $\mathrm{V}_{\mathrm{j}}$. This error is known as the cost function; it signifies the accuracy of the classifier. Mean square error is the mostly used cost function and is given by:

$\operatorname{MSE}=\frac{1}{N} \sum_{i=1}^{N}\left(A_{i}-V_{i}\right)^{2}$

\subsection{Multi-Class Classification of GTE Performance Using MLP FFNN}

Multi-class performance classification of GTE is a problem of building a system that accurately maps an input feature space to output space of three or more classes [32]. Multi-class classification has been used for object classification [33], speech tagging and recognition [34], [35], text categorisation and information retrieval [36]. Figure 3. Shows a architecture of multi-class neural network model for GTE system performance classification.

A multi-class, also known as K-class, neural network classification problem can be expressed as; for $n$-dimensional feature space $\mathrm{h}_{\theta}$, and a training dataset $X_{\mathrm{tr}} \mathrm{C} \mathrm{h}_{\theta}$, where each element $\mathrm{x}$ in $X_{\mathrm{tr}}$ is associated with class label C, C $€$ Class Labels $=\left\{\mathrm{C}^{1}, \mathrm{C}^{2} \ldots \mathrm{C}^{\mathrm{k}}\right\}, \mathrm{k} \geq 3$.

A neural network $\mathrm{F}$ can be trained on $X_{\text {tr }}$ such that given a set of feature vector $x \in X, F(x) \in$ Class Labels. $\mathrm{F}$ is a neural network whose weights are computed by a neural learning algorithm.

For a given neural network, the input and output at a hidden node $\mathrm{j}$, is given by:

$I_{j}^{h}=\sum_{i=1}^{N} w_{i j}^{h} x_{i}$

$\mathrm{Z}_{\mathrm{i}}=g^{h}\left(I_{j}^{h}\right), \mathrm{j}=1, \ldots, \mathrm{H}$

Where $\mathrm{x}_{\mathrm{i}}$ is the input of the feature vector $\mathrm{X}, w_{i j}^{h}$ is the weight association with input $x_{i}$ to the $i^{\text {th }}$ hidden node, $H$ is the number of the hidden node, $\mathrm{g}^{\mathrm{h}}(\bullet)$ is the activation function used in the hidden layer.

In the output layer, each node $\mathrm{V}_{\mathrm{k}}$ has the input and output as:

$I_{k}^{o}=\sum_{i=1}^{N} w_{i j}^{o} z_{j}$

$\mathrm{y}_{\mathrm{k}}=g^{o}\left(I_{j}^{o}\right), \mathrm{k}=1, \ldots, \mathrm{M}$

where $z_{j}=$ output value from the $j^{\text {th }}$ hidden unit,

$w_{k j}^{o}=$ weight associated with $\mathrm{j}^{\text {th }}$ hidden node and the $\mathrm{k}^{\text {th }}$ output nodes

$\mathrm{g}^{\mathrm{o}}()=$ the activation function used in the output layer which is the sigmoidal function.

\section{Case Study System}

The focus of this paper is on gas processing system which involves compression, heating, cooling and separation of various hydrocarbon components. The system is made up of trains of high capacity gas compressors, driven by gas turbine engines (GTE). The GTEs are the pivot of these operations because they drive the gas compressors and their exhaust gas is used as heating medium for NGL or LNG extraction processes.

A single train of gas compression system comprises of gas generator (GG), combustion chamber (CC), GT, power turbine (PT) with associated gear box and gas compressor (mostly rotary or centrifugal compressor). The interactions of the components and their associated parameters give rise to power, performance, efficiency and characteristics of the GTE system. The diagram in Figure 4 highlights components level, parameters and functional interactions within gas processing system.

In this paper, performance of the GTE system is analysed and classified using EGT sensor data for incipient fault detection. Seventeen thermocouple temperature sensors are used to monitor exhaust gas temperature of the GTE, one of the critical parameters of system which affects many system variables and is affected by other variables as well. For example, temperature and mass flow of the exhaust determine the speed of the power turbine that drives the rotary compressors which in turn compress the process gas. As the load of the driven compressors increases, the fuel flow increases, leading to increase in firing temperature of the gas turbine [37]. The speed of the compressor, gas turbine, power turbine and the firing temperature depend on the fuel flow and 
quality of fuel (constituents of fuel, wet/dirty fuel) and compressor discharge pressure of the GG. Sensor data from this system was collected periodically over a period of thirty days with two hundred and fifty data instances. The seventeen thermocouple sensors are the seventeen input features and three classes as target outputs, making the data size of 3000 ( 150 by 20 matrix). The data was pre-processed and normalised using $\mathrm{z}$-score and minmax normalisation techniques. FFNN with back propagation model was used to predict and classify the performance of GTE system using exhaust gas temperature data, with seventeen sensor data set as inputs to the model and the target output as classes of health state or performance condition of the system. The decision table below in table 1 indicates EGT ranges for a given performance and their class labels.

Given a training dataset $\left\{\left(\mathrm{x}^{(1)}, \mathrm{y}^{(1)}\right),\left(\mathrm{x}^{(2)}, \mathrm{y}^{(2)}\right), \ldots,\left(\mathrm{x}^{(\mathrm{m})}, \mathrm{y}^{(\mathrm{m})}\right)\right\}$

Let $\mathrm{L}=$ total number of layers in the network

$\mathrm{S}_{\mathrm{L}}=$ number of unit (excluding bias unit) in layer $l$

In this analysis, $\mathrm{L}=3$ (that is, input layer, one hidden layer and output layer).

$\mathrm{S}_{1}=17$ neurons in input layer

$S_{2}=(8,9,10,11,12,14,15)$, number of neurons in hidden layer for different runs of the experiment.

$\mathrm{S}_{3}=3$ neurons in output layer

$\mathrm{y} \in \mathrm{R}^{\mathrm{k}} ; \mathrm{k} \geq 3$

$\mathrm{C}^{1}=\left[\begin{array}{l}1 \\ 0 \\ 0\end{array}\right]$ Optimal performance of GTE

$C^{2}=\left[\begin{array}{l}0 \\ 1 \\ 0\end{array}\right]$ Average performance of GTE

$C^{3}=\left[\begin{array}{l}0 \\ 0 \\ 1\end{array}\right]$ Abnormal performance of GTE

\section{Results of the GTE Performance analysis}

The classification results shows that $S_{2}=7,9$ and 10 give accurate classification results as indicated in figure 5; meaning that the multiclass neural network can be used to monitor the performance of the GTE using the EGT sensor data. Poor classification accuracy is achieved when the number of neurons in the hidden layer $S_{2}$ is 13 . The Essence of performance monitoring of GTE system is to detect the start of average performance of the system so the operations of the gas processing plant can be properly managed without unnecessary system upset or stoppage. This decisional information if communicated on time could be used to reduce impact of oil and gas operations such as uncontrolled venting and flaring, oil release or spill, in extreme case fire outbreak which may impact on the business, environment or may lead to fatality.

\section{Conclusions and Future Works}

This paper has provided intelligent maintenance solution through integration of condition-based predictive maintenance strategy into integrated oil and gas processing system development life cycle. The reliability and maintenance challenges in oil and gas have grossly affected normal operations of the system, which in turn leads to serious safety, health, business and environmental impacts. Reduction of impacts of oil and gas operations can be achieved by properly monitoring performance of the system for incipient fault detection.

Total performance condition monitoring of oil and gas processing system can play a major role in providing early warning of potential failure and performance deterioration of the system. One of the key operating and control parameters associated with performance efficiency of the GTE system operations is the EGT. In this paper, MLP FFNN multi-class classification technique was used to monitor and classify performance of GTE system which drives rotary compressors for NGL extraction. Performance classification of the system was carried out on EGT data from seventeen thermocouple temperature sensors. The GTE system performance was classified into optimal performance (EGT range of $1275-1426^{\circ} \mathrm{F}: \mathrm{C}^{1}$ ); average performance (EGT range of 1175 $1270^{\circ} \mathrm{F}$ : $\mathrm{C}^{2}$ ); abnormal performance (EGT range of $1075-1170^{\circ} \mathrm{F}$ : $\left.\mathrm{C}^{3}\right)$. The classification accuracy was high $(100 \%$ correct classification) when the number of neurons in the hidden layer of the model were $S_{2}=7,9$ and $10 . S_{2}=13$ gave relatively poor classification result. This information is very useful for effective operation and maintenance management of the system.

This research categorises oil and gas system data into monitoring, performance and condition datasets. In the course of the research project, condition dataset such as vibration data and bearing temperature shall be analysed for fault detection estimation and prediction using wavelet packet, Hidden Markov and Bayesian classification techniques

\section{Figures and Tables}
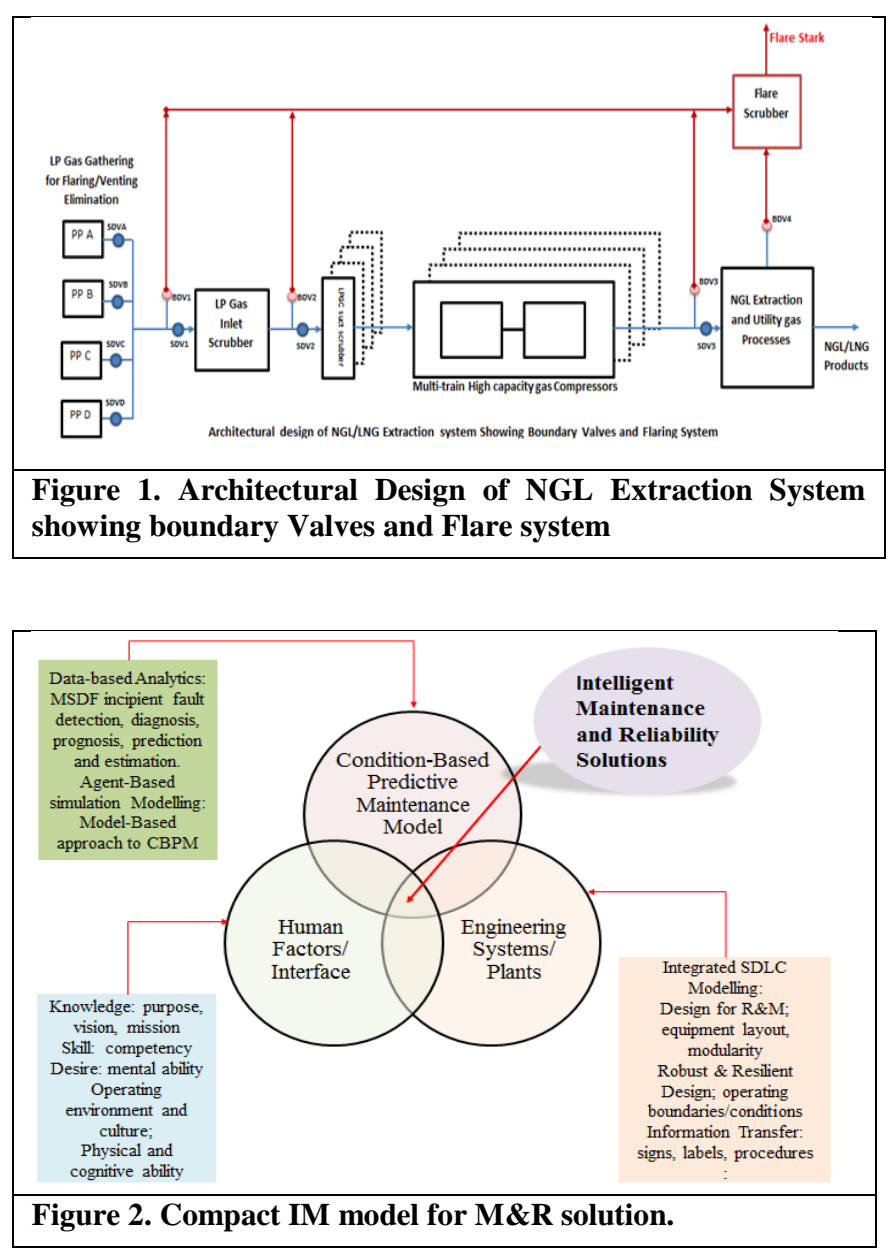

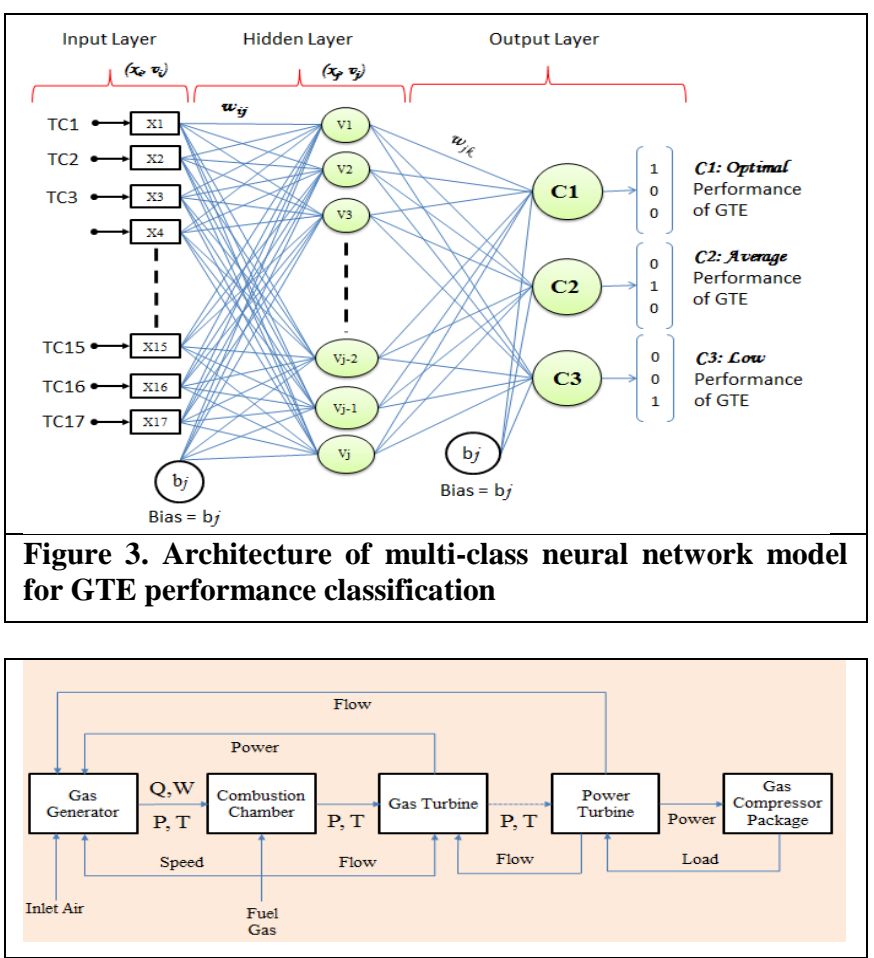

Figure 4: Components and Functional Interactions within gas processing system

Table 1. Decision table showing EGT ranges and GTE performance class labels

\begin{tabular}{|l|l|c|l|}
\hline EGT Range & GTE Performance & $\begin{array}{l}\text { Class } \\
\text { Label }\end{array}$ & $\begin{array}{l}\text { Required } \\
\text { Actions }\end{array}$ \\
\hline $1275-1426^{\circ} \mathrm{F}$ & $\begin{array}{l}\text { Optimal } \\
\text { Performance }\end{array}$ & 1 & No action \\
\hline $1175-1270^{\circ} \mathrm{F}$ & $\begin{array}{l}\text { Average } \\
\text { Performance }\end{array}$ & 2 & $\begin{array}{l}\text { Plan for } \\
\text { inspection; } \\
\text { incipient fault }\end{array}$ \\
\hline $1075-1170^{\circ} \mathrm{F}$ & $\begin{array}{l}\text { Abnormal } \\
\text { Performance }\end{array}$ & 3 & $\begin{array}{l}\text { Needs urgent } \\
\text { maintenance } \\
\text { actions }\end{array}$ \\
\hline
\end{tabular}

\section{REFERENCES}

[1] Anastasia Rodina. Burning Through: Reducing Associated Petroleum Gas Flaring To Enhance Natural Resources Governance. Law in Transition Journal 2016

[2] Joseph Fiksel. Designing Resilient, Sustainable System. Environ. Sci. Technol. 2003, 37, 5330-5339

[3] 3. Lee, J., Ni, J., Djurdjanovic, D., Qiu, H., \& Liao, H. (2006). Intelligent prognostics tools and e-maintenance. Computers in Industry, 57(6), 476-489.

[4] Edino, M. O., Nsofor, G. N. and Bombom, S. L. (2010). Perceptions and attitudes towards gas flaring in the Niger Delta, Nigeria. Environmentalist. 30: 67-75.

[5] Eyoh Jeremiah, Roy Kalawsky. Predictive Control Approach to Complex Engineering Systems' (Oil and Gas Process Plants) Reliability and Life Cycle Management through
Multi-Sensor Data Fusion. Wolfson School Conference Paper, 2017.

[6] NNPC Annual Statistical Bulletin. http://www.nnpcgroup.com/PublicRelations/OilandGasStatis tics/AnnualStatisticsBulletin/MonthlyPerformance.aspx.

[7] Bruno Gervet, March 2007. Gas Flaring Emission Contribute to Global Warming. Renewable Energy Research Group, Division of Architecture and Infrastructure, Lulea University of Technology, Lulea Sweden.

[8] World Bank. 2004. Regulation of associated gas flaring and venting : a global overview and lessons from international experience. Global gas flaring reduction - a public-private partnership : No. 3. Washington, DC: World Bank. http://documents.worldbank.org/curated/en/59056146876556 5919/Regulation-of-associated-gas-flaring-and-venting-aglobal-overview-and-lessons-from-international-experience

[9] David T. Allen. Emissions from oil and gas operations in the United States and their air quality Implications. Journal of The Air \& Waste Management Association 2016, VOL. 66, NO. 6, 549-575. http://dx.doi.org/10.1080/10962247.2016.1171263

[10] Alisson Cardoso Gomes da Silva, Silvio de Oliveira Junior (2010). Performance Evaluation of Turbomachinery in the Petroleum Exploration and Production Area. Proceedings of ENCIT 2010. 13th Brazilian Congress of Thermal Sciences and Engineering.

[11] Rainer Kurz, Klaus Brun (2016) GAS TURBINE PERFORMANCE Asia Turbomachinery and Pump Symposium Singapore. February 2016

[12] Rainer Kurz (2005) Gas Turbine Performance. Proceedings of the Thirty-Fourth Turbomachinery Symposium, 2005

[13] Rainer Kurz, Dary D. Legrand. Field Performance Testing of Gas Turbine Driven -Compressor Sets. Proceedings of the $28^{\text {th }}$ Turbomachinery Symposium

[14] Lee, J., Ni, J., Djurdjanovic, D., Qiu, H., \& Liao, H. (2006). Intelligent prognostics tools and e-maintenance. Computers in Industry, 57(6), 476-489. http://doi.org/10.1016/j.compind.2006.02.014

[15] Levrat, E., \& Iung, B. (2006). TELMA : A full emaintenance platform. Centre de Recherche en Automatique de Nancy (CRAN) - UMR 7039. Retrieved from http://www.incose.org.

[16] Starr, A., Willetts, R., Hannah, P., Hu, W., Banjevic, D., \& Jardine, A. K. S. (n.d.). Data fusion applications in intelligent condition monitoring. www.wseas.us/elibrary/conferences/crete2002/papers/444-802.pdf

[17] Hall, David L; Llinas, J. (n.d.). Handbook of Multisensor Data Fusion: The Electrical Engineering and applied signal Processing Series.

[18] Bernard Schmidt, Ulf Sandberg, L. W. (2004). Next Generation Condition Based Predictive Maintenance. Methods, 13306, 4-11. http://www.divaportal.org/smash/get/diva2:748786/FULLTEXT01.pdf

[19] Masoud Asgarpour, John Dalsgaard Sorensen (2018). Bayesian Based Diagnostic Model for Condition Based Maintenance of Offshore Wind Farms. Energies - Open Access Journal of Energy Research, Engineering and Policy. 
[20] Nagi Z. Gebraeel, Mark A. Lawley, Rong Li, Jennifer K. Ryan (2005). Residual-life distributions from component degradation signals: A Bayesian approach. IIE Transactions (2005) 37, 543-557.

[21] Parikshit Mehta, Andrew Werner, Laine Mears (2015). Condition based maintenance-systems integration and intelligence using Bayesian classification and sensor fusion. Journal of Intelligent Manufacturing archive, Volume 26 Issue 2, April 2015, Pages 331-346

[22] Francesco Di Maio, Selina S. Y. Ng, Kwok-Leung Tsui, Enrico Zio. Naïve Bayesian Classifier for Online Remaining Useful Life Prediction of Degrading Bearings. MMR2011, Jun 2011, China. pp.1-14, 2011

[23] Alice E. Smith, David W. Coit, Yun-Chia Liang (2010). A Neural Network Approach to Condition Based Maintenance: Case Study of Airport Ground Transportation Vehicles. IEEE Transactions on Automation Science and Engineering, Vol. 7, No. 1, January 2010

[24] Ali Kattan, Rosni Abdullah, and Zong Woo Geem. Artificial Neural Network Training and Software Implementation Techniques. Nova Science Publishers, Inc., 2011.

[25] Daniel T Larose and Chantal D Larose. Discovering knowledge in data: an introduction to data mining. John Wiley \& Sons, 2014.

[26] Jose Manuel Ortiz-Rodrguez, Hector Rene Vega-Carrillo, Jose Manuel Cervantes Viramontes, and Ma del Rosario Martnez-Blanco. Robust Design of Artificial Neural Networks Methodology in Neutron Spectrometry. INTECH Open Access Publisher, 2013.

[27] Guoqiang Peter Zhang. Neural networks for classification: a survey. Systems, Man, and Cybernetics, Part C: Applications and Reviews, IEEE Transactions on, 30(4):451 \{462, 2000.

[28] D. Baillie and J. Mathew, "A comparison of autoregressive modeling techniques for fault diagnosis of rolling element bearings", Mechanical Systems and Signal Processing, Vol. 10, pp. 1-17, 1996.
[29] B. Paya, M. Badi and I. Esat, “Artificial neural network based fault diagnostics of rotating machinery using wavelet transforms as a preprocessor", Mechanical Systems and Signal Processing, Vol. 11 (5), pp. 751-765, 1997.

[30] Hongjun Lu, Rudy Setiono, and Huan Liu. Neurorule: A connectionist approach to data mining. In VLDB, volume 95, pages $11\{15,1995$.

[31] Gaurav Kumara, Sandeep Sharmab, Hasmat Malikc (2016). Learning Vector Quantization Neural Network Based External Fault Diagnosis Model for Three Phase Induction Motor Using Current Signature Analysis. 6th International Conference On Advances In Computing \& Communications, ICACC 2016, 6-8 September 2016, Cochin, India. Procedia Computer Science 93 ( 2016 ) 1010 - 1016.

[32] Guobin Ou,Yi Lu Murphey (2006). Multi-class pattern classification using neural networks. Pattern Recognition Society, Pattern Recognition 40 (2007) 4 - 18

[33] Y.L. Murphey, Y. Luo, Feature extraction for a multiple pattern classification neural network system, IEEE International Conference on Pattern Recognition, August 2002.

[34] E. Brill, Some advances in transformation-based part of speech tagging, In: AAAI Conference, vol. 1, 1994, pp. 722 727.

[35] Y. Even-Zohar, D. Roth, A sequential model for multiclass classification, in: SIGDAT Conference on Empirical Methods in Natural Language Processing, 2001, pp. 10-19.

[36] C. Apte, F. Damerau, S.M. Weiss, Automated learning of decision rules for text categorization, Inf. Syst. 12 (3) (1994) 233-251.

[37] Guoqiang Peter Zhang. Neural networks for classification: a survey. Systems, Man, and Cybernetics, Part C: Applications and Reviews, IEEE Transactions on, 30(4):451 \{462, 2000.

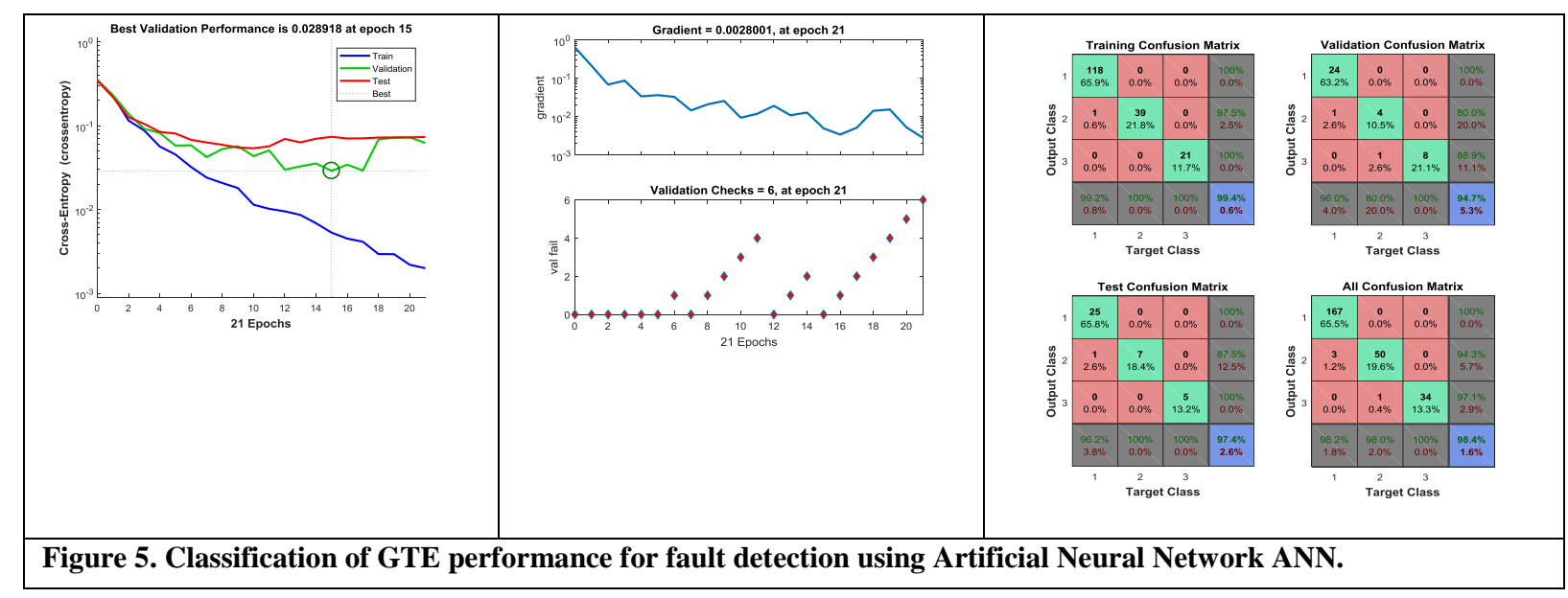

